This item was submitted to Loughborough's Research Repository by the author.

Items in Figshare are protected by copyright, with all rights reserved, unless otherwise indicated.

\title{
Large-volume and low-frequency atmospheric glow discharges without dielectric barrier
}

PLEASE CITE THE PUBLISHED VERSION

PUBLISHER

(C) American Institute of Physics

\section{VERSION}

VoR (Version of Record)

\section{LICENCE}

CC BY-NC-ND 4.0

\section{REPOSITORY RECORD}

Shi, J.J., and Michael G. Kong. 2019. "Large-volume and Low-frequency Atmospheric Glow Discharges Without Dielectric Barrier". figshare. https://hdl.handle.net/2134/5177. 
This item was submitted to Loughborough's Institutional Repository (https://dspace.lboro.ac.uk/) by the author and is made available under the following Creative Commons Licence conditions.

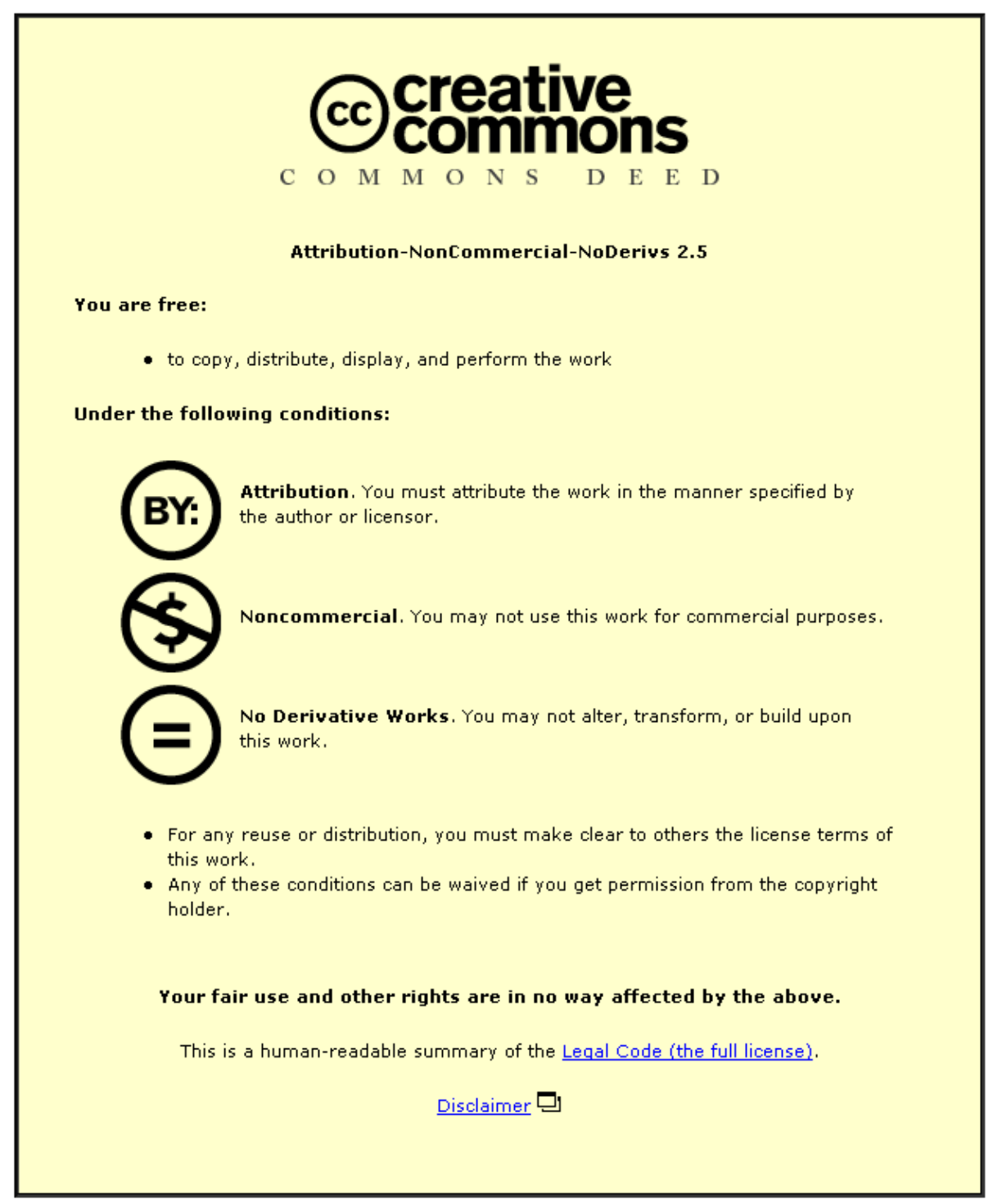

For the full text of this licence, please go to: http://creativecommons.org/licenses/by-nc-nd/2.5/ 


\title{
Large-volume and low-frequency atmospheric glow discharges without dielectric barrier
}

\author{
J. J. Shi and M. G. Kong ${ }^{\text {a) }}$ \\ Department of Electronic and Electrical Engineering, Loughborough University, Loughborough, \\ Leicestershire LE11 3TU, United Kingdom
}

(Received 4 June 2004; accepted 28 January 2005; published online 25 February 2005)

\begin{abstract}
It is widely believed that, at low frequencies of $1-100 \mathrm{kHz}$, the generation of atmospheric pressure glow discharges (APGD) requires a dielectric barrier added to at least one electrode. This letter reports the experimental observation of a uniform and stable APGD generated between two bare electrodes without a dielectric barrier over a wide frequency range from $20 \mathrm{kHz}$ to $260 \mathrm{kHz}$. Below $70 \mathrm{kHz}$, it is shown that preionization in the rising phase of the applied voltage is important and plasma generation occurs in the voltage-falling phase. Mechanism of barrier-free APGD is found to be different from both atmospheric dielectric-barrier discharges and radio-frequency APGD. (C) 2005 American Institute of Physics. [DOI: 10.1063/1.1879095]
\end{abstract}

Large-volume glow discharges generated at atmospheric pressure are currently one of the most important topics in gas discharge physics because of their immense potentials for numerous applications. ${ }^{1}$ These atmospheric pressure glow discharges (APGD) are nonthermal capacitive plasmas generated between two parallel electrodes. For the frequency range of $1-100 \mathrm{kHz}$, it is widely believed that the necessary condition to generate stable APGD is to insulate at least one electrode with a dielectric barrier. ${ }^{2}$ In this letter, we report the observation of stable and uniform glow discharges between two bare electrodes without a dielectric barrier at frequencies from $20 \mathrm{kHz}$ to $260 \mathrm{kHz}$. They are different from previously reported barrier-free APGD that are generated in $\mathrm{dc}^{3}$ at $60 \mathrm{~Hz},{ }^{4}$ or at radio frequencies in the megahertz range. ${ }^{5,6}$ In our experiments, barrier-free APGD were generated in helium between two parallel stainless-steel electrodes of $2 \mathrm{~cm}$ diameter and with a gap size of $1.5 \mathrm{~mm}$. The electrodes were not water cooled.

With a nanosecond intensified CCD camera system (Andor iStar DH720 with 5 ns gate), the generated barrierfree plasma was found to be diffuse, uniform, and free of any obvious streamers. Electrical measurements with a digital oscilloscope of $300 \mathrm{MHz}$ bandwidth and $2.5 \mathrm{Gs} / \mathrm{s}$ sample rate show a repetitive and smooth trace of the discharge current, without short-lived current spikes associated with a glow-toarc transition of $\sim 10 \mathrm{~ns}$ duration. Figure 1 shows the current density and voltage of the barrier-free APGD at four different excitation frequencies of $20 \mathrm{kHz}, 50 \mathrm{kHz}, 70 \mathrm{kHz}$, and $260 \mathrm{kHz}$. Current density is very low, typically below $0.5 \mathrm{~mA} / \mathrm{cm}^{2}$ apart from the $260 \mathrm{kHz}$ case for which the peak current density is $1.5 \mathrm{~mA} / \mathrm{cm}^{2}$. Such low current density levels are similar to that of atmospheric dielectric-barrier discharges (DBD). At $20 \mathrm{kHz}$, their power density is found to be $0.1 \mathrm{~W} / \mathrm{cm}^{3}$, much lower than that of thermal plasmas and also less than $0.3 \mathrm{~W} / \mathrm{cm}^{3}$ typical of atmospheric DBD. ${ }^{7}$ Furthermore, the barrier-free APGD can be operated for many hours without the danger of thermal runaway. These observations strongly suggest that the generated barrier-free atmospheric plasmas are glow discharges.

\footnotetext{
${ }^{\text {a) }}$ Author to whom correspondence should be addressed; electronic mail: m.g.kong@lboro.ac.uk
}

Current-voltage characteristics of the barrier-free APGD make an interesting comparison with that of atmospheric DBD. At $20 \mathrm{kHz}$, the discharge current of the barrier-free APGD has one large peak every half cycle of the applied voltage, similar to atmospheric DBD. However, this is where the similarity ends. As shown in Fig. 1, the discharge event occurs in the voltage-falling phase and this is very different from atmospheric DBD for which the discharge event occurs in the voltage-rising phase. Given that bare electrodes are used in the barrier-free APGD, both the voltage-rising phase and the voltage-falling phase should have similar gap voltage and so the observation of strong discharge events only in the voltage-falling phase is intriguing. At $50 \mathrm{kHz}$ and $70 \mathrm{kHz}$, there appear two competing discharge events, one in the voltage-rising phase and the other in the voltage-falling phase. Increasing the excitation frequency to $260 \mathrm{kHz}$, the current spike seen previously in the voltage-falling phase
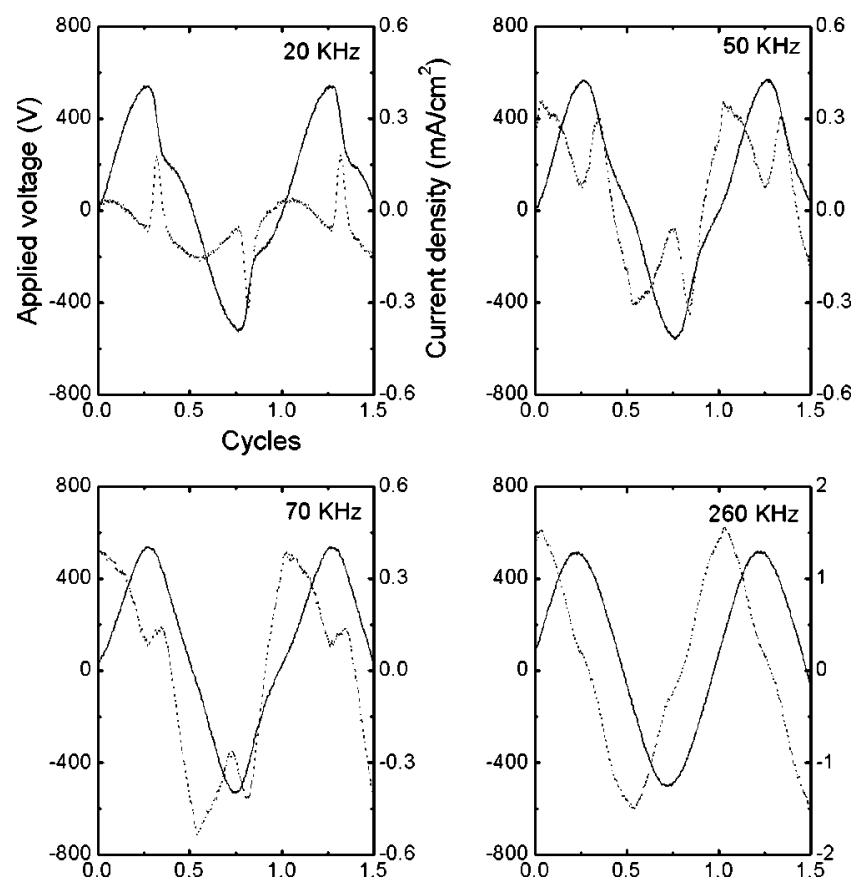

FIG. 1. Measured current density (dashed curve) and voltage (solid curve) of a barrier-free APGD at four different frequencies. 

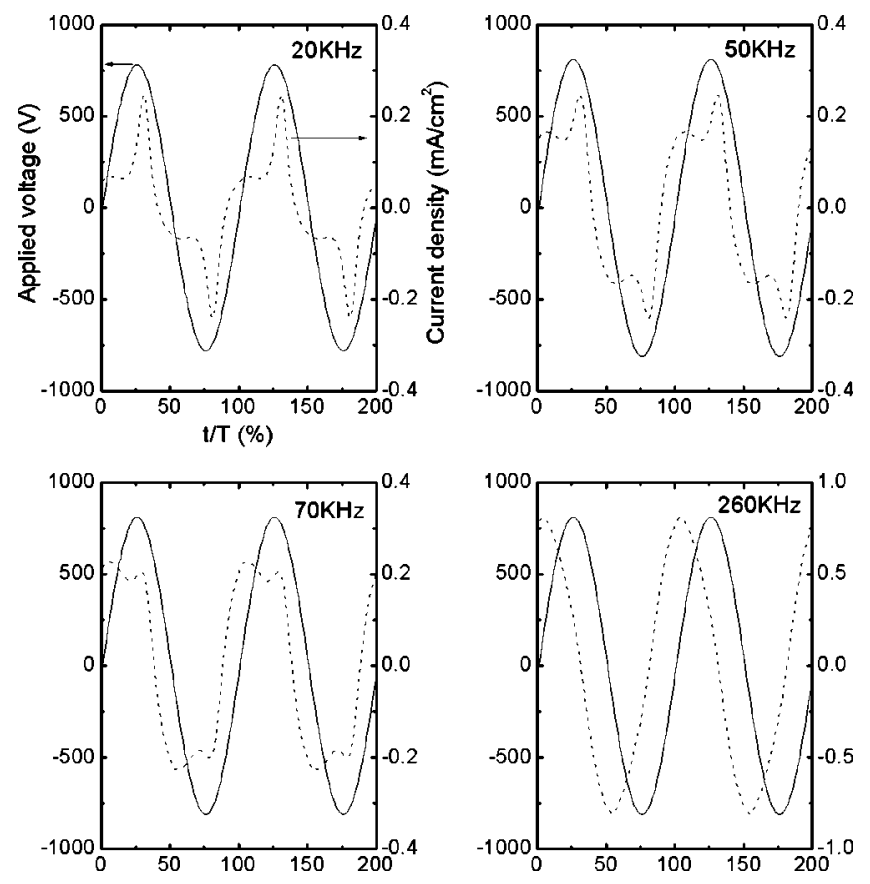

FIG. 2. Simulated current density and voltage traces for the four cases of Fig. 1.

disappears and the current-voltage pattern is now similar to radio-frequency APGD.,

To understand discharge events in the voltage-falling phase, we have developed a simple hydrodynamic plasma model based on our previous work ${ }^{7}$ but with two plasma species only, namely electrons and helium ions. Figure 2 shows the numerically simulated discharge current density and applied voltage for all four frequencies. The applied voltage used in the simulation is necessarily greater than the measured voltage because stepwise ionization and Penning ionization $^{7}$ are not included in our model. In terms of the wave form, numerical prediction resembles closely experimental results of Fig. 1. At $20 \mathrm{kHz}$, there is a strong discharge event in the voltage-falling phase and none in the voltage-rising phase. As the frequency increases, an additional discharge event in the voltage-rising phase emerges and eventually at $260 \mathrm{kHz}$ the discharge event at the voltagerising phase disappears. Discharge mechanism of barrier-free APGD appears to be different from both atmospheric DBD and radio-frequency APGD.

Figure 3 shows at $20 \mathrm{kHz}$ simulated spatial profiles of electron density, helium ion density, and the electric field at different instants during the first half cycle of the applied voltage when the cathode is on the right-hand side. At Point 1 , most electrons are located near the cathode and the electric field is very small with negligible space charges. Under the influence of the applied voltage, electrons are driven toward the anode, and at Point 2 many electrons are lost to the anode. As a result, the space-charge field remains small and the electric field in the gap is set up largely by the applied voltage. This is confirmed by the similar slopes of the electric field at Point 1 and Point 2 in Fig. 3(d). The lack of sufficient space charges keeps the electric field below the breakdown field and as such there is no discharge at Point 2. At Point 3, the applied voltage is the largest leading to increased gas ionization and increased charge particle densities. As shown in Fig. 3(d), the resulting increase in the Downloaded 20 Aug 2009 to 158.125 .80 .71 . Redistribution subject
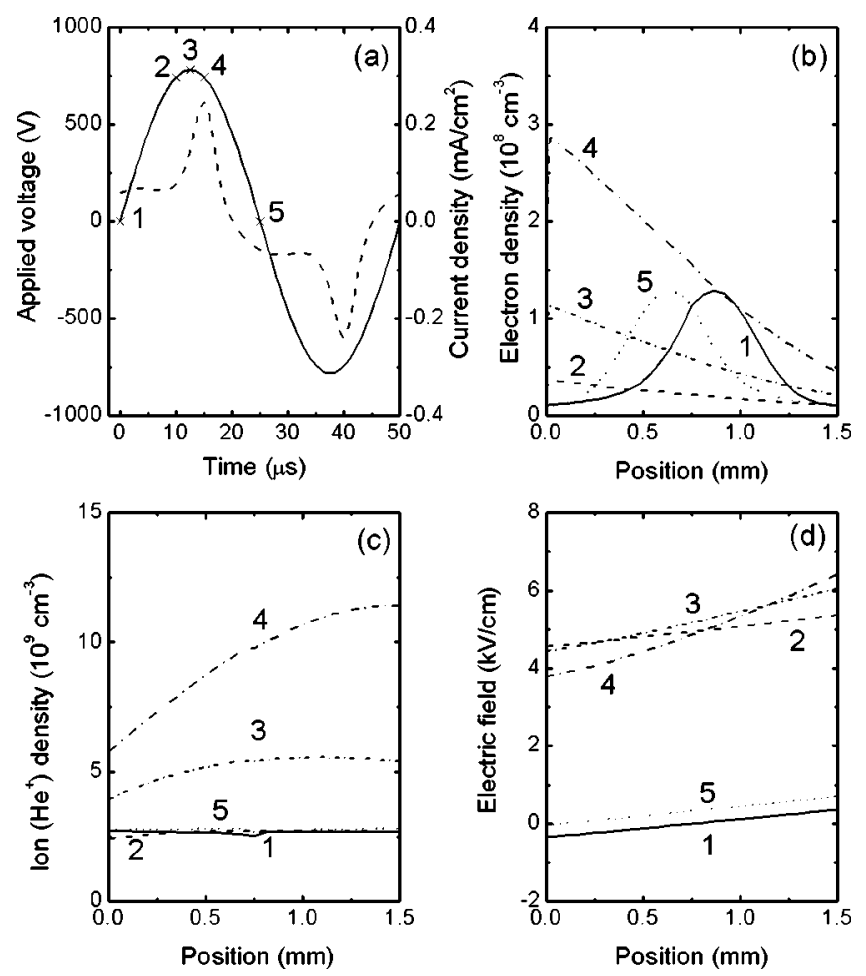

FIG. 3. Simulated (a) discharge current density and applied voltage; (b) electron density; (c) ion density; and (d) electric field for a $20 \mathrm{kHz}$ barrierfree APGD.

space-charge field is greater near the cathode, and the nearcathode electric field is now higher than that of Point 2. So, in the time duration from Point 3 to Point 4, more electronion pairs are produced thus creating more space charges and increasing further the electric field near the cathode. Consequently, at Point 4, the electric field near the cathode exceeds the breakdown field at a location near the cathode and an avalanche is induced there leading to the large current peak in Fig. 3(a). In other words, sufficient preionization prior to breakdown throughout the voltage-rising phase is necessary to provide substantial space charges and the latter then add to the applied voltage to elevate the electric field above the breakdown electric field. This is why the discharge event of barrier-free APGD occurs in the voltage-falling phase.

Further evidence to support the above interpretation is obtained from the ionization rate and the loss rate of electrons to the electrodes. Using the gap voltage, we estimate the electron loss rate from the time required for an electron to reach the anode from the middle of the gas gap. In Fig. 4, it is shown that the gap voltage needs to be about $880 \mathrm{~V}$ for electron gain to balance out electron loss. This corresponds to an electric field of $880 \mathrm{~V} / 1.5 \mathrm{~mm}=5.9 \mathrm{kV} / \mathrm{cm}$. If the electric field exceeds this threshold at any point within the gas gap, an avalanche is likely to be triggered. Figure 3(d) shows that the peak electric field is $5.2 \mathrm{kV} / \mathrm{cm}$ at Point 2 and $6.2 \mathrm{kV} / \mathrm{cm}$ at Point 4, suggesting gas breakdown is only possible at Point 4. This is precisely the findings of Fig. 3(a) that breakdown occurs at Point 4 but not Point 2 even though these two points have an identical gap voltage.

Discharge events in the voltage-rising phase observed at higher frequencies are found to be associated to significant electron acceleration by the rapid oscillating field of the applied voltage. This increases the kinetic energy of electrons resulting greater gas ionization. Equally importantly the to AIP license or copyright; see http://apl.aip.org/apl/copyright.jsp 


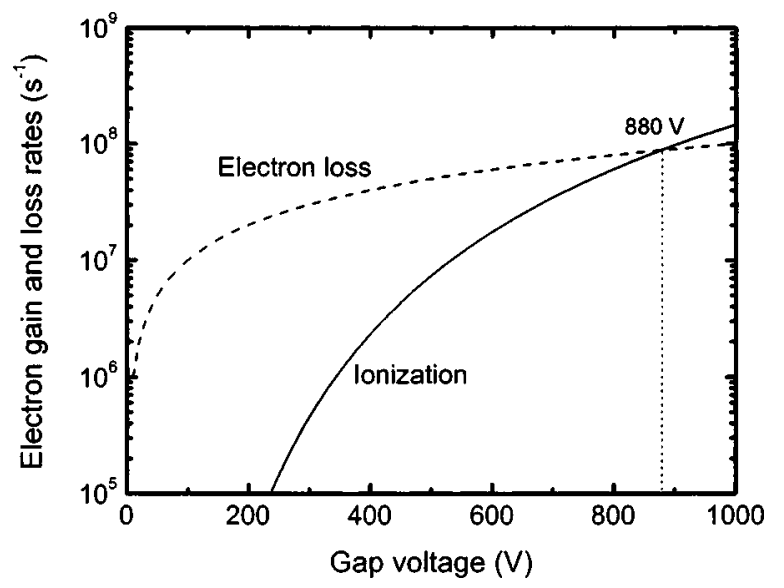

FIG. 4. Simulated electron production and loss rates as a function of the gap voltage.

rapid changing voltage traps more electrons within the electrode gap thus reducing electron loss to the electrodes. The combination of these two factors allows for the rapid establishment of an adequate electric field for gas breakdown in the voltage-rising phase when the excitation frequency is sufficiently high.
In summary, experimental observation of barrier-free APGD was reported at low frequencies from $20 \mathrm{kHz}$ to $260 \mathrm{kHz}$ and numerical simulation was used to understand their discharge mechanism. It has been established that at $20 \mathrm{kHz}$ rapid electron loss to the electrodes prevents sufficient space charges from being built up and as such gas breakdown in the voltage-rising phase is not possible. Instead, preionization in the rising phase of the applied voltage is important to create sufficient space charges to compensate for electron loss, leading to gas breakdown in the voltagefalling phase.

The authors acknowledge the technical help of Dr. Yun Yang.

${ }^{1}$ J. R. Roth, Industrial Plasma Engineering, Principles, Vol. I (Institute of Physics Publishing, Philadelphia, PA., 1995).

${ }^{2}$ S. Kanazawa, M. Kogoma, T. Moriwaki, and S. Okazaki, J. Phys. D 21, 838 (1988)

${ }^{3}$ R. H. Stark and K. H. Schoenbach, J. Appl. Phys. 85, 2075 (1999).

${ }^{4}$ M. Laroussi, I. Alexeff, J. P. Richardson, and F. F. Dyer, IEEE Trans. Plasma Sci. 30, 158 (2002).

${ }^{5}$ J. Park, I. Henins, H. W. Herrmann, G. S. Selwyn, J. Y. Jeong, R. F. Hicks, D. Shim, and C. S. Chang, Appl. Phys. Lett. 76, 288 (2000).

${ }^{6}$ J. J. Shi, X. T. Deng, R. Hall, J. D. Punnett, and M. G. Kong, J. Appl. Phys. 94, 6303 (2003).

${ }^{7}$ M. G. Kong and X. T. Deng, IEEE Trans. Plasma Sci. 31, 7 (2003). 